\title{
Investigating the use of digital manipulatives for storytelling in pre-school
}

\author{
Cristina Sylla ${ }^{\mathrm{a}, *}$, Clara Coutinho ${ }^{\mathrm{a}}$, Pedro Branco ${ }^{\mathrm{b}}$, Wolfgang Müller ${ }^{\mathrm{c}}$ \\ ${ }^{a}$ Ciec/engageLab, University of Minho, 4710-057 Braga, Portugal \\ ${ }^{\mathrm{b}}$ engageLab/Algoritmi, University of Minho, 4800-058 Guimarães, Portugal \\ ${ }^{\mathrm{c}}$ Media Education and Visualization (MEVIS), University of Education, 88250 Weingarten, Germany
}

\section{A R T I C L E I N F O}

\section{Article history:}

Received 9 December 2013

Received in revised form

5 October 2015

Accepted 14 October 2015

Available online $\mathrm{xxxx}$

\section{Keywords:}

Digital manipulatives

Tangible interfaces

Storytelling

Emergent literacy

Language development

Preschool children

\begin{abstract}
A B S T R A C T
Research has identified a need for design of interactive products for children, as well as long-term studies that investigate the effects of its use in the classroom environment. Following the design and development of a digital manipulative system for storytelling, which involved preschool children and teachers, the investigation presented here reports findings from a four-month evaluation of the system that was carried in a Portuguese preschool involving 24 pairs of children. During the four months the researchers were able to observe children's interaction with the digital manipulative system that was not biased by the novelty of the system or by time constrains. The gathered data showed that children used the digital manipulative system to create stories and play language games, which are activities that foster the development of oral language and emergent literacy, and are formally targeted in the preschool curriculum. The system provided challenge and adventure, motivating children to collaboratively explore and create narratives, empowering each child to actively participate in the task.
\end{abstract}

(C) 2015 Elsevier B.V. All rights reserved.

\section{Introduction}

The work presented here is part of a broader study that was carried for a period of four years in a Portuguese preschool. ${ }^{1}$ The overall aim of the study was to design and evaluate a digital manipulative system ${ }^{2}$ that stimulates storytelling and oral language development in preschool children.

The study was structured in two main phases: the first one was dedicated to the design and implementation of the interface, and extended for a period of three years, involving six pre-school classes (ages five) and six preschool teachers [3]. Following the implementation, the researchers carried out three interventions at

\footnotetext{
* Corresponding author.

E-mail addresses: sylla@engagelab.org (C. Sylla),ccoutinho@ie.uminho.pt (C. Coutinho), pbranco@dsi.uminho.pt (P. Branco), mueller@md-phw.de (W. Müller).

1 This work returns to a study presented in the doctoral dissertation of the first author [1].

2 The term digital manipulatives has been coined by Resnick to designate a new generation of computationally enhanced manipulative materials that enable children to interact with digital information [2]. In the scope of this work we will use the terms digital manipulatives, tangible interfaces (TUIs), or tangible systems as synonyms.
}

preschool for a period of around one year. The first one, (which we report here) was performed with 24 pairs of children from two preschool classes, who interacted with the interface during freeplay time for a period of four months, and aimed at investigating how children used the system and the kind of activities in which they involved during free-play time. The second intervention was carried out in collaboration with a preschool teacher with a group of 20 children during three months, and investigated to which extent the use of the digital manipulative system promoted the development of language abilities that are relevant for formal literacy learning. Finally, the last intervention studied the narratives created by 27 pairs of pre-schoolers, while using the interface for a period of six months [4].

The motivation to develop digital manipulatives for preschoolers emerged out of:

- The need expressed by leading researchers in the field of Child Computer Interaction "for research in the design of interactive products for children, related methodology, as well as a scientific account of the interaction between children and technology" [5]:2.

- The need expressed by educational professionals and researchers for learning materials that meet children's physical and cognitive needs [6]; 
- The need for more long-term evaluations, including evaluations in the classroom $[7,8]$;

- The potential of digital manipulatives to involve children in expressive and exploratory learning activities [2,9].

The intervention reported in this article had an exploratory nature, and aimed at investigating if the interface was intuitive to use for the children, if they would choose to play with it among the other activities they could do during free-play time, and if yes, whether it was capable of involving children in meaningful activities, or on the other hand if children would lose interest after the initial use. Overall we wanted to investigate the extent to which the use of digital manipulatives can support the development of oral language and emergent literacy [10]. These competencies play a major role in the learning of reading and writing, and are essential for the development of children's personal, social and academic skills. Three research questions were formulated: Is the interface attractive and intuitive to use for the children? In what kind of activities do the children engage, and is their involvement long lasting, or merely a result from the new digital artefact? Can digital manipulatives contribute to the development of early literacy, promoting creative thinking and the construction of narratives?

Before presenting the digital manipulative system and the study, we will briefly highlight the importance of oral language development in the pre-school years and then provide a short overview of the design process explaining the choices we have made.

\section{Background and related work}

\subsection{Language development and early literacy}

The development of oral language is among the major challenges that children face during the preschool years; this is also the 'best' learning period to formally learn the language [11]. Language develops primarily to communicate with others, and through the interaction with others, in a process that is essentially social and interactive [12]:103. At the same time language mediates learning, and is a tool to organize the world [13]:6 empowering children to express themselves, to communicate with others and to participate actively in educational activities ([13]; [14]:8 and [15]).

Yet, the acquisition and development of oral language is a long and particularly complex process, which reaches its critical development during the preschool years, a period of rapid conceptual and lexical acquisition.

During this period children begin to develop "emergent literacy skills", which are "developmental precursors to conventional reading and writing skills" [16]:21. The variety of rich literacy experiences is fundamental for the development of emergent literacy, and is directly related with children's degree of exposure and active participation in literacy environments, where they interact with meaningful materials, within social contexts that scaffold and encourage emergent literacy attitudes [17-20].

Storytelling is a creative and playful way of linguistic exploration $[21,22]$ that promotes the development of oral language $[23,24,21]$, providing opportunities for creative thinking and social interaction [22,25], helping children learn to express themselves and communicate with others, gradually acquiring the discourse rules [26]. Stories help children to "develop more sophisticated language structures, accumulate more background information and have more interest in learning to read. In addition active participation in literary experiences enhances the development of comprehension, oral language and a sense of story structure" [24]:646.

\subsection{Storytelling technology in school}

The use of technology in school may play an important role in supporting the development of oral language and emergent literacy in a collaborative peer context, however such potential has been "under-explored" [27]:81. Well-designed interactive technology has the potential to offer four key characteristics of effective learning environments: active engagement, collaborative learning, frequent and immediate feedback, and connections to real world contexts [28,29].

Yet, the use of technology in preschool is still uncommon $[30,31]$ even though a significant number of teachers consider it useful as preparation for school [32]. The use of technology to support literacy development is even more infrequent, as stated by Yarosh and collegesYaroshetal2011. In an extensive examination of 137 long papers presented at the Interaction Design and Children Conference (IDC) for the period between 2002 and 2010 the authors reported that technology to support literacy development was the focus of merely $8 \%$ of all papers (with a decreasing trend).

As opportunities for IDC, the authors expressed the need for more long-term evaluations, and the need to investigate whether the technologies remain compelling for the children after the novelty effect is gone [7]:143. They also challenged researchers to design for a larger variety of ages, as the majority of IDC papers targeted children between six and twelve. These results confirm findings from previous reports, which concluded that the great part of research on technology and children over the last two decades addresses mostly older children with a pick around ten years of age, [33-35].

Just a few years before the development of tangible technology [36], examples of desktop computer applications that target the development of collaborative storytelling for children were created by [37], who first included young children, technologists, and educators in the design of the technology [38]. One of these projects the KidStory [39] involved around 100 children aged between five and seven from two schools in England and Sweden. The project resulted in the development of a collaborative environment for storytelling (by using a Single Display Groupware system that supports several mice plugged into the computer), which allowed children to create non-linear structured stories.

The PictoPal [40] is a more recent example of an application for desktop computers designed to foster the development of emergent reading and writing skills in four and five years old children, which was carried at preschool involving children and teachers.

\subsection{Touch and tangible technology}

More recent projects such as Fiabot, Castor, or VisMo are applications for tablet devices. The Fiabot [41] explores the creation of interactive and multimedia stories. Similar to our study, but involving two primary school classes (instead of preschoolers), this project extended for a period of four years, and investigated the development of technology that supports existing teaching and learning practices. Castor [42], a project carried out at primary school with the collaboration of teachers, consists of a tablet application in which children can create and edit stories outdoors, exploring the role of the environment and the potential of mobile technology for connecting outdoors structured learning and experience. VisMo [43] is a set of playful applications for preschoolers that run on multi-touch tabletops to promote creativity and collaboration. Other projects, such as Scratch Junior [44] or the Interactive Sticker Book [45], use storytelling to introduce programming concepts for children.

Developments that use tangible technologies for storytelling vary widely, some approaches use books enhanced with embedded sensors and electronics, thus extending the experience provided by traditional books. Some relevant examples here are the MagicBook [46], Telescrapbooks [47], or the Bridging Book [48].

Tangible Story Listening Systems, which according to Cassel may play a unique role in supporting emergent literacy [27]:81, 
emphasize speaking/listening aspects. Some examples are TellTale [49], StoryMat [50], Sam the CastleMate [51], or $t$-words [52]. Other systems that explore the creation of narratives are POGO [53], or Jabberstamp [54]. POGO combines a set of tangible tools, which enable children to create multimedia narratives, encouraging experimentation, and sharing of stories. Jabberstamp allows children to enhance their graphical narratives with voice and sounds.

TOK (Touch, Organize, Create) the tangible technology that we present here uses physical blocks for manipulating virtual story elements. One of the great advantages of TOK (and of tangible technology in general) over applications that run on computers or touch technology is their potential to support and promote collaboration, as users can manipulate and share the physical elements. Similar to the Siftables [55], which consist of small squares with an LCD display, TOK uses physical blocks to manipulate virtual content, enabling children to choose among a great range of story elements (up to 250 blocks) empowering them to create their own original narratives. The blocks allow multiple users to simultaneously manipulate the digital content, giving them freedom of movement and equal control of action, thus supporting collaboration [56,57], and "facilitating communication and "transparency" of interaction between multiple collocated users" [58].

TOK's robustness, its easy setup and intuitive use are further characteristics that differentiate it from other tangible systems. Despite their potential to engage children in storytelling activities, many of the referred tangible technology is quite complex to set up and use on a regular basis in the classroom (e.g., Pogo, StoryMat, Sam the CastleMate, or the MagicBook) especially in the preschool environment where robustness and ease of use are core issues; or the tilt-based menu might be difficult for the children to manipulate (Siftables), moreover, some of the discussed interfaces represent conceptual prototypes (Telescrapbooks).

\section{Digital manipulatives for playful learning-the case of TOK}

Whilst it is beyond the scope of this paper to give a detailed description of the development process, in the following section we will briefly present some relevant insights that informed the design of the final interface. For more information the reader may refer to [3].

\subsection{Design and development}

Following a Design Based Research methodology [59,60], the design and development of the interface involved six classes of five years old pre-schoolers, during a period of three years and followed an iterative, cyclical process of designing, testing, and redesigning $[61,62]$ always incorporating the feedback and the suggestions provided by the children and the teachers in the development of new prototypes.

As an example, to assess how children create narratives we used a low-fi prototype that consisted of an A4 cardboard and a set of paper cards with drawings representing characters, places and actions. By observing the children placing the cards in rows on the paper prototype we noticed that they were concerned with aligning the picture cards, based on that observations we choose to use slots for placing the cards in the functional prototype. This way we could simplify children's task, while offloading extra cognitive processes, as children would not have to worry about alignment issues.

Relatively to the size of the platform, we noticed that some children felt compelled to fill the complete cardboard with the picture cards, which lead us to reduce the size of the final prototype.
As the children placed the picture cards on the paper prototype following different patterns (Fig. 3.1) while telling their stories some began on the top, others on the bottom, others placed the cards on the middle of the prototype, and some used the space as a drawing - the final interface needed to identify: the content of each picture card, its location, and the order each card entered the system. This would allow users to randomly place the cards on the platform, without having to follow any determined order. Additionally the system needed to support connections between cards, or groupings of cards.

Outgoing from the idea of using picture cards, we chose tangible blocks for manipulating the virtual story elements, as blocks allow multiple users to simultaneously manipulate the content, thus supporting peer collaboration.

The interaction followed three development principles: visibility, rapidity and reversibility of actions [63]. The blocks make the interaction explicit and open [56,58]; give rapid feedback of the performed actions (placing a block on the platform immediately displays its digital content) and every performed action is reversible by removing the block from the platform, which is particularly relevant for content exploration [64].

A tangible element that revealed to be extremely important was the microphone, as it strongly motivated children to verbalize their stories. Initially the microphone was not part of the system, however as we were video recording children's interaction with the functional TOK prototype we decided to connect a microphone to the video camera (that was placed behind the children) to improve the audio quality of the collected data. When the children saw the microphone they immediately appropriated it, and it became part of the interface, from there on the child that was speaking also hold the microphone, though the recording function was not implemented.

\subsection{Short overview of the digital manipulative system}

Presently, the TOK prototype is composed by an electronic platform that connects to a tablet through Bluetooth or to a computer via USB, and 23 physical blocks to manipulate the digital content (Fig. 3.2).

In the current implementation the system detects up to 250 different blocks, however that number can be increased. The surface of the electronic platform has slots for placing the blocks. Both the back of the blocks as well as the platform have magnets on their surface that correctly snap the blocks to the platform, making it easy for the users to place the blocks while simultaneously assuring a stable contact between the blocks and the platform. Each block has a sticker with a picture of what it represents on the upper side and a conductive pattern in its base, which is detected by the capacitive sensor on the basis of the electronic platform (Fig. 3.3).

Placing a block on the platform displays the corresponding digital content on the devices screen, creating a direct mapping between input and output. The sequence of blocks placed on the platform unfolds a narrative. Content corresponding to the pictureblocks is displayed on the screen following the order in which the blocks are placed, when a block is removed from the platform it disappears from the screen. The depiction of the characters on the displays is dynamic, and selected based on the story flow from the underlying storytelling engine, thus strengthening the narrative experience.

The blocks represent classical settings and actants in narratives for children, - heroes and opponents [65] - and are composed by characters, objects and nature elements (Fig. 3.4).

The familiarity of the characters enables recreating variations from the original stories, as well as to create original stories. The five different scenarios (a castle landscape, a forest, a desert, 


\section{ARTCOLE IN PRESS}
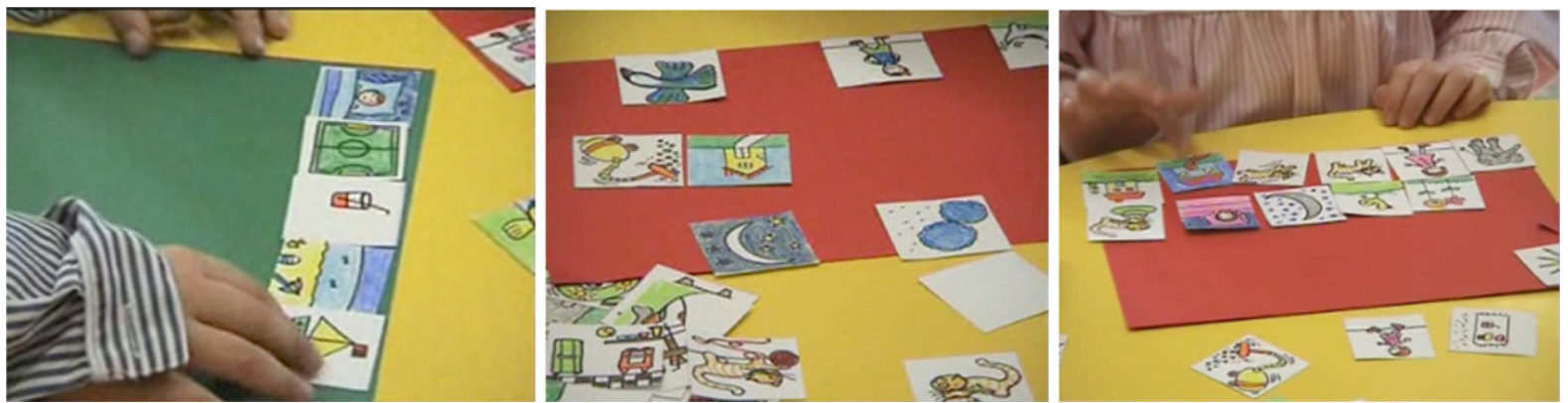

Fig. 3.1. Children creating stories with the paper prototype.
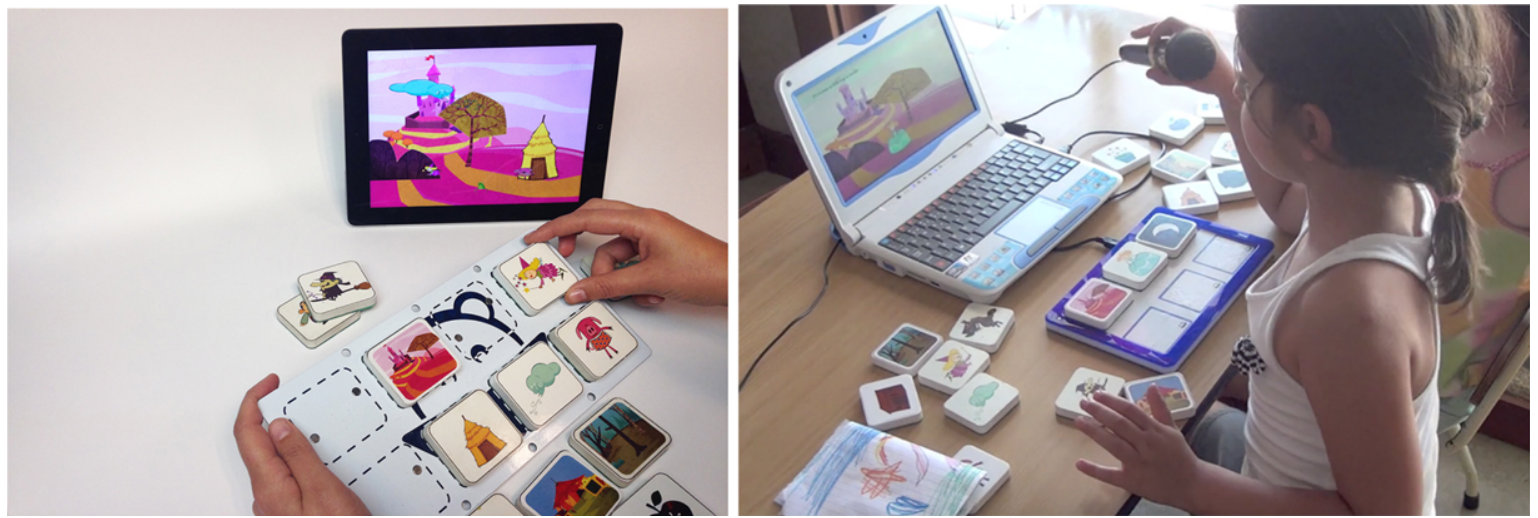

Fig. 3.2. TOK running on a tablet device (left), TOK running on a computer (right).
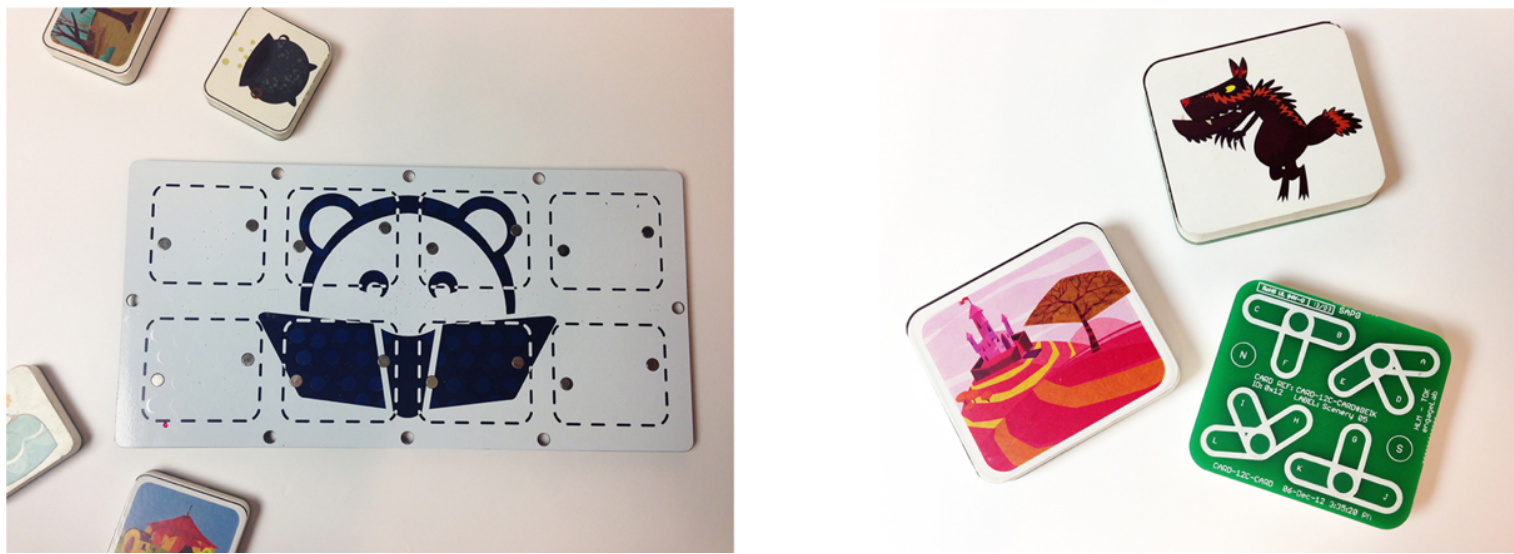

Fig. 3.3. Electronic platform with Bluetooth (left), back and front side of blocks (right).

woods and a circus) enable locating the stories in different settings (Fig. 3.5).

The scenarios are dynamic; this means that each scenario has some elements (trees, cactus, rocks) that are displayed randomly each time the scenario is used. Children can change the scene, mix and remix the characters, and as there is only visual feedback (except for the ambient sounds), children can imagine and create their own spoken narratives.

\subsubsection{Relations between the story elements}

The story world was modelled to bring a certain degree of surprise in the unfolding of the narrative, and was designed using behaviour trees (BTs). The principle followed in the design of the BTs was to model a world that young children know from traditional story plots. Therefore we defined four types of entities: settings, characters, objects and nature elements. The settings are the background image where the action takes place. The nature elements (e.g., day, night, wind) enable the configuration of the story settings, e.g., the moon turns the day into night, the cloud blows everything away from the scene. The characters and the objects are categorized as good, bad or neutral; bad characters attack the good ones, good characters defend the neutral and help each other; both good and bad characters can join forces to defend or attack their opponents. Specific objects like a caldron or a flowerpot can be used to knock down bad characters and defend the good ones. A bad object (e.g., a poisoned apple) diminishes the health of a character; on the contrary a good object (e.g., a carrot) increases the health of a character.

Each entity has its BT, which defines its behaviour as well as the interactions with the other entities. Since each entity has its own pre-defined rules, and its behaviour depends on the other entities that are also placed on the platform, there are no predefined stories, nor a linear narrative, which brings a certain degree of unpredictability and surprise of the narrative outcome, allowing 

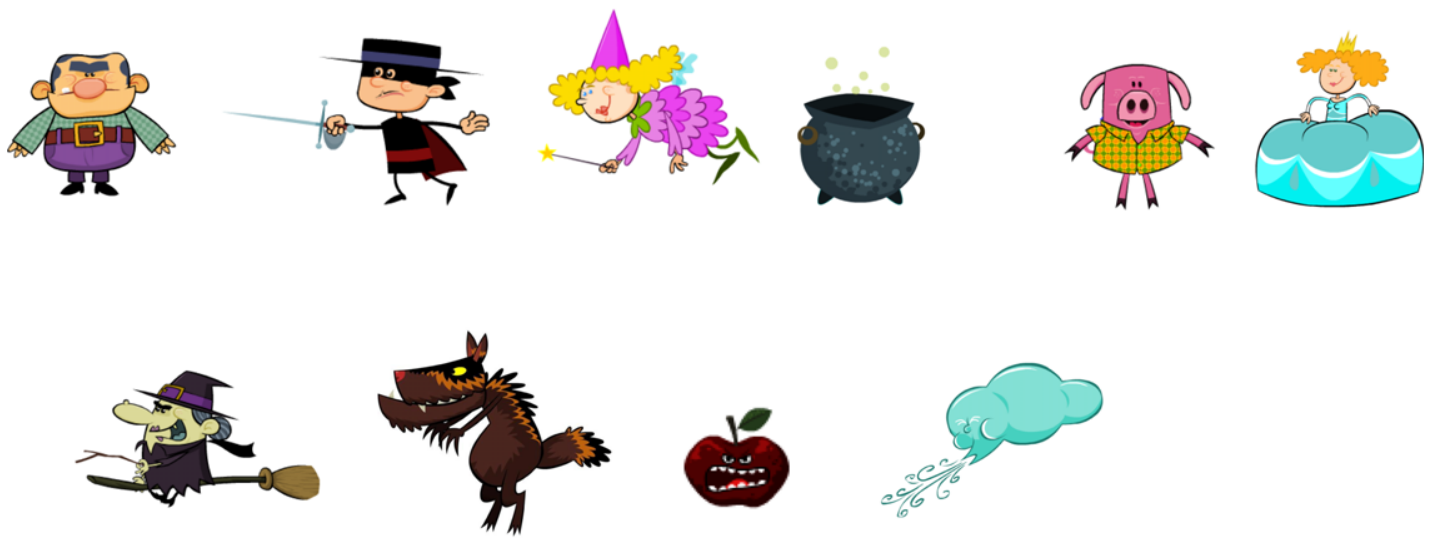

Fig. 3.4. Some of the characters and objects.
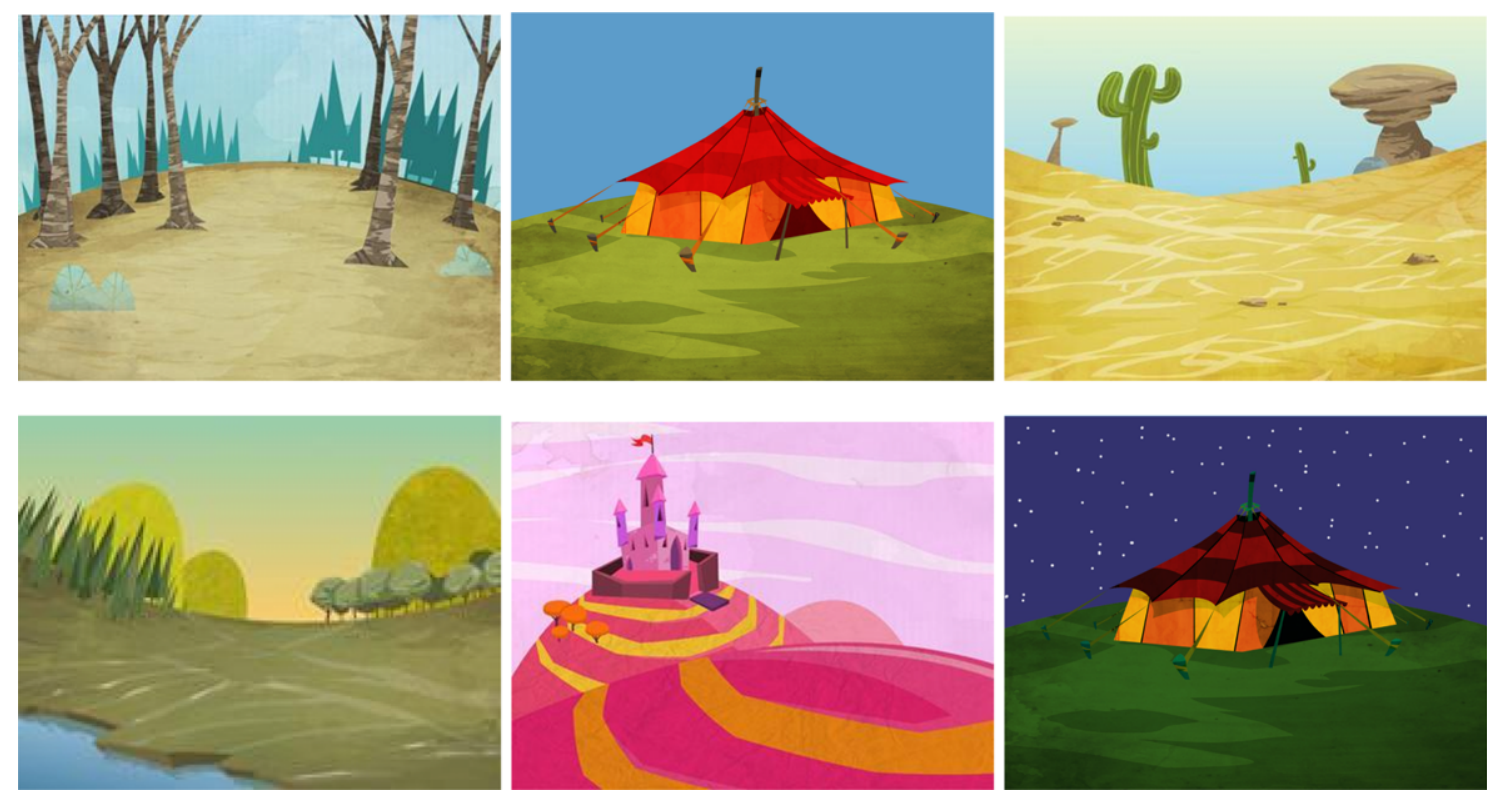

Fig. 3.5. The different settings that can be used to place the story in different settings, a scenario placed together with the moon (bottom right).

Table 3.1

Examples of interactions between the characters (according to the placed blocks).

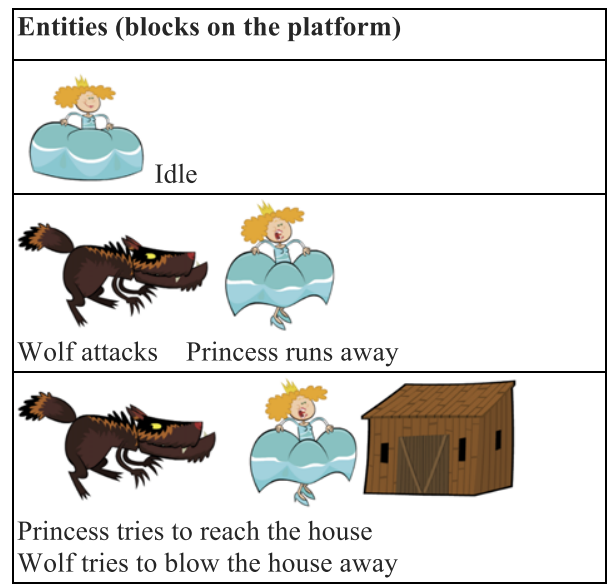

users to create a wide variety of different stories. We will illustrate this with an example (Table 3.1): the princess is alone on the scene, where she is on idle behaviour, as soon as a second block is placed on the platform, the princess' BT detects the new entity

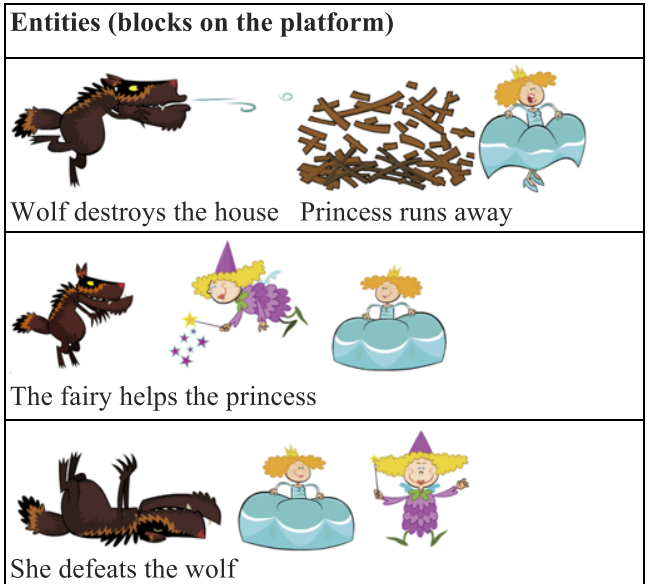

and triggers her behaviour (according to the princess' BT). The wolf attacks the princess, she tries to escape, and now what happens further on the screen will depend on the blocks that will be placed next. There are several possibilities to help the princess, users can 
place a house, where she will try to hide (the wolf will try to blow the house away), or place another character to help (fairy, Zorro), or use the caldron to knock the wolf. Or as the children found out, simply remove the wolf, or the princess from the platform.

\section{User study: assessing children's use of TOK in the classroom}

\subsection{Method}

As previously mentioned the study described here reports on the first intervention after the development of TOK. The research followed an exploratory approach, as in this first evaluation stage of the working prototype the researchers wanted to gather information on how children handle the interface, whether it was intuitive to use and engaging (or if children would lose interest after the novelty disappeared) and if TOK was capable of involving children in meaningful activities, promoting the development of oral language and emergent literacy.

\subsubsection{Participants}

The intervention involved 24 pairs of children aged five from the same pre-school but from two parallel classes. None of the classes had participated in the design of the digital manipulative system, or had seen it before the intervention.

\subsubsection{Procedure}

The study took place during a period of four months, and was carried in the classroom during children's free-play time. Free-play time is an integrant part of the pre-school activities, and takes place everyday after lunch for around $45 \mathrm{~min}$. During free-play time children can choose between four different "activity areas" (house, constructions, library and computer) to play on their own (without teacher's intervention). Each of the two participant classes had a TOK interface, which was placed in the computer area. The children could use TOK in pairs as long as they wanted (within the $45 \mathrm{~min}$ of the free-play time period); after finishing, another pair could use the interface. These procedures are part of the guidelines for multimedia use (during free-play time) in both classes. As always several children wanted to use TOK, the pairs were mostly assigned by the teachers, and consisted of five pairs of girls, seven pairs of boys and 12 mixed pairs.

\subsubsection{Data collection}

Two times a week on a regular basis a researcher visited the classes and collected the data using a video camera discreetly placed behind the interface. To better capture children's verbalizations a microphone was connected to the camera and placed on the table between the children and the interface. The researcher stood at the back of the room, observing and taking notes. In order to avoid any bias caused by the novelty of the digital artefact, the collection of the data began some weeks after children started using TOK.

Besides video recordings the data was collected using direct observation techniques, field notes, as well as semi-structured interviews with the preschool teachers. The interviews were carried in the classroom (at the end of the school day) once a month using a flexible interview script that intended to obtain teachers' perceptions of children's work with the interface, and its overall impact on children's oral verbalizations, as well as the extent to which the use of TOK was noticed in the daily classroom routines.

\subsubsection{Data analyses}

The observation of the videos, which were later transcribed and coded using Content Analyses [66] led to the classification

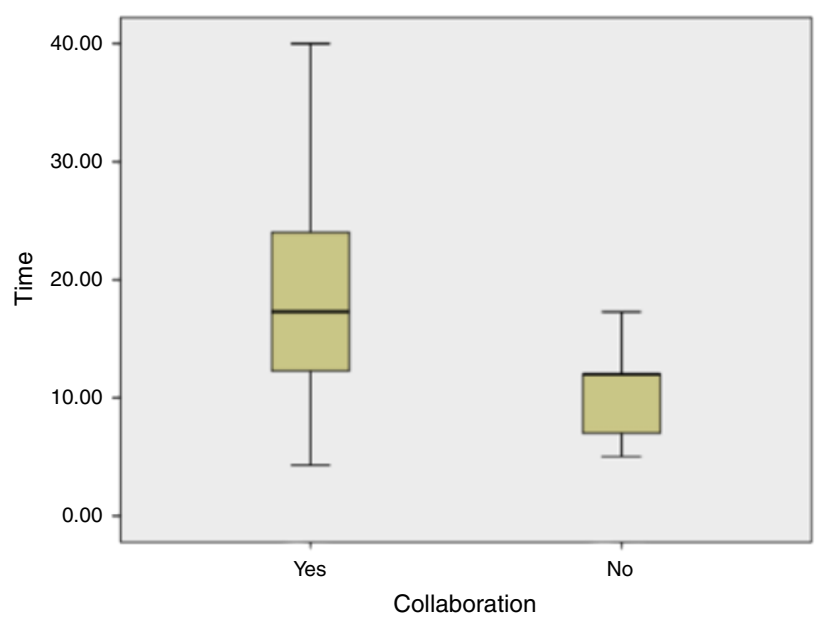

Chart 5.1. Distribution values of the interaction time vs. collaboration.

of a set of categories, which were coded based on the amount of time that children spent using the interface, as well as aspects like collaboration, and the kind of activities carried (Table 5.1).

To guarantee the reliability of the coding process two independent coders discussed the content of each category analysing and discussing video samples in order to attain the maximum consensus [67], afterwards, each coder codified the videos independently. The inter-coder coefficient of agreement was calculated using Cohen's kappa formula [68], and revealed an agreement of 0.953 (95, $3 \%)$.

The data was analysed through descriptive statistic techniques; when necessary the variables were crossed using crosstabs and when the variables were nominal the Chi Square test was applied. The Student $t$-test was used to compare means when the dependent variable was numeric, the level of significance considered was $<0.05$ or $5 \%$.

\section{Results}

Table 5.1 presents the coded categories of children's interaction with TOK, which will be discussed in the following subsections.

\subsection{Interaction time and collaboration}

Considering that the amount of time that children play with technology is directly related to the pleasure of using it, we measured the time children played with TOK. The average interaction time of each child was $16.64 \mathrm{~min}$, whereby $75 \%$ of the children verbalized the wish to play longer (as usually more than one pair used TOK during the 45 min of free playtime, the pairs that followed could not always play as long as they wanted).

The pairs that collaborated used TOK almost twice as long as the pairs that did not collaborate, with a mean interaction time of $19.24 \mathrm{~min}$, versus $10.3 \mathrm{~min}$ (Chart 5.1). The Student's $t$-test for independent groups confirmed that the pairs that collaborated (71\%) spent statistically considerable more time with TOK than the pairs that did not collaborate (value of proof of 2.261, which is significant for the level of $p>0.05$ ), indicating a relation between interaction time and collaboration.

Children coordinated the interaction following different patterns, sometimes they spontaneously took turns to speak, sometimes they claimed their turn to continue the story (or start a new one), or they created the stories by building on each other's contributions. Children also divided tasks, when one child was narrating the other placed the blocks according to the unfolding of the story, as illustrated by following example (pair of girl and boy): 
Table 5.1

Coded categories of the interaction with the interface.

Categories of children's interaction with TOK

$\begin{array}{ll}\begin{array}{l}\text { Interaction time } \\ \text { Wish to play longer }\end{array} & \text { Minutes } \\ \text { Collaboration } & \text { Yes/No } \\ \text { Yreate narratives } & \text { Yes/No } \\ & \text { Use characters to help others } \\ & \text { Remove characters from the platform to help others/or to escape danger } \\ & \text { Use objects to knock down characters } \\ \text { Interaction strategies and narrative creation } & \text { Lift blocks from the platform to bring characters to life } \\ & \begin{array}{l}\text { Order/sort blocks to have a good overview } \\ \text { Address characters with direct speech }\end{array} \\ & \begin{array}{l}\text { Incorporate songs in the story } \\ \text { Embodied construction of the narrative }\end{array} \\ & \text { Use different voices for the different characters } \\ & \text { Choice of a scenario to locate the stories } \\ \text { Implications of the choice of characters or elements on the story plot } & \text { Wish to explicitly finish the narratives }\end{array}$

Boy-The witch transformed that place [circus] into an enchanted forest [removes the circus block and places the forest block].

Girl-Once upon a time there was a pig that was dead in the forest [places pig], suddenly the great witch appeared [places witch], and then a strong wind came [places cloud] and took the pig and the witch to a place far, far away....

Girl - [whispering to her peer] - now you will take the forest, and place the lake.

\subsection{Interaction strategies and narrative creation}

Well-designed technology is easy to use, ideally having a low threshold to start but also supporting more sophisticated projects [69]; during the evaluation of TOK we aimed to investigate how children would manipulate the physical blocks. We observed that the functioning of the manipulative system was very intuitive for the children. After some initial experimentation where they explored the blocks and the relations between them, most of the time children used TOK to create stories (71\%), while some used TOK more as a game (29\%) playing language games, testing different fight combinations, or trying to knock down different characters. Specially boys seemed to find a great pleasure in doing this, e.g., after knocking down the witch with the flowerpot, a boy says "Touché" and he and his pair begin to dance and sing. However, some pairs of boys also embedded the fights within a story:

Boy A-(singing): we like the night, when it is night the wolves came,

Boy B-Yes, and they will come today, and every day.

Boy A-and the ogres also came, when it strikes midnight! Huhu.... And now it comes the super hero, the knight. And now we will kill the wolf, and the witch too, but the knight lost the fight.

In the pairs of girls and the mixed pairs a great level of story dramatization was observable, for a detailed analysis of children's narratives the reader may refer to [4].

Children quickly understood the functioning of the system and used this knowledge to shape their stories, for instance when a character was dead/defeated they simply lifted the physical block from the platform and placed it again, thus bringing the character to life (used by $70 \%$ of the children), e.g., "the princess died of

\footnotetext{
3 When lifting the blocks from the platform they leave the system, and consequently disappear from the screen, by placing the blocks on the platform they enter the system again and are displayed on the screen. This way children could
} control the "life" of the characters. eating this apple, I will give you a kiss" (places the prince, and lifts the block of the princess, bringing the princess to life again).

Another strategy was knocking down unwished characters using the caldron or the flowerpot (50\%). Further, children used characters to help others, or removed characters from the platform to help others/or to escape danger.

Children often began the narratives by defining a location for their stories, and changed the scenario according to the unfolding of the plot. Except for two pairs all used different settings, locating the great majority of the stories in the castle landscape (34\%), or the forest (23\%), only a group used the desert landscape. Following a story (told mainly by the girl that assumed the leading position in the pair), which she named "Walking along the long paths" exemplifies how the different settings inspired the children:

Once upon a time there was a prince who wanted to marry a princess. He was walking from one side to the other, looking for her. So he decided to travel, and travelled, there were strong winds, until he came to a village [places block with the circus landscape], but he did not like that village. He came to the desert [places block with the desert landscape] and finally he came to a castle [places block with the castle landscape]. It was a beautiful day and he had the feeling he was going to find a princess and he was going to marry her, but suddenly the witch appeared. They run to the forest [places block with the forest landscape] and the witch died. He returned to the castle [places block with the castle landscape] with the princess and they finally got married.

\subsection{Embodied creation of the narratives}

The physical manipulation of the story elements seems to have strongly contributed to children's immersion (absorption and active participation [70]:4) in the story world, as they become physically involved in the task they were performing. Elements that reflected children's embodiment were: playing different voice intonations for the various characters (29\%), singing or mimicking ambient sounds (24\%), as well as addressing the story elements (characters and objects) with direct speech (48\%), e.g., the wolf is running after the pig, children place a house, as the pig does not hide in the house the girl says: "what is going on little dummy? Just go inside the house!" Sometimes children also spoke with each other about the characters, e.g., two boys try to knock down the wolf with the flowerpot, as they miss the target, one boy explains to the other: "the wolf is a cheater he is doing hard-headed".

Further, the children expressed their feelings of enthusiasm or anxiety physically, e.g., standing up from their chairs, waving arms, clapping hands, or jumping joyfully. Some groups were so excited with the stories that they called the teacher and told the whole class what had happened, spontaneously sharing their experience. 
In such moments other children would join around TOK to see what happened, taking part in the interaction by commenting and giving suggestions.

\subsection{Reflections over the narrative}

Around a third of the pairs (37.5\%) ordered or sorted the physical blocks on the table to have a good overview of all the elements, some pairs also used that strategy to plan the stories in advance. For instance one boy builds rows with the blocks saying: "That way is easier to find".

Children reasoned about which characters or objects they ought to choose in order to achieve a certain story outcome. They considered consequences and implications for the unfolding of the narrative, e.g., when placing certain elements that had magic powers, such as the apple, which poisoned the good characters. They reflected over the implications of choosing certain characters or elements, e.g., they preferred to place the brick house instead the straw or the wooden house since it offered a secure shelter. Children supported their narratives, explaining the unfolding of the plot, e.g., "the fairy became little, but she grew again as she took a magic portion". Or they reasoned about what happened in the story: "the angry man died because he ate the poisoned apple". Also, by creating variations of the traditional stories the children reflected on the narrative:

There was a village where there were a wooden house, a straw house and a brick house. There lived a little pig, which had two brothers, he wanted to invite them to visit him but there was also a wolf and the little pig was afraid that his brothers would not come. The brothers came and stood with him, they hid in one house and then went to another one, so they could escape the wolf.

Further, children often explicitly ended their stories ("and this is the end of our story", or "victory, victory, here ends our story").

\subsection{Teachers' opinion regarding the use of TOK in the classroom}

As previously mentioned, along the intervention the researcher carried semi-structured interviews with the preschool teachers. The teachers referred that TOK was used everyday in both classes, and children did not use the computer during that time. As several children wanted to use the interface, the teachers opted to create a list of users to have an overview of the children that had already used TOK, so that everyone could use it.

Both teachers reported that the use of the manipulative system motivated the children to engage in creative narrative construction, as well as playing various language games. They considered that the use of TOK stimulated children's imagination and creativity, giving them new ideas for their stories. According to both teachers, the interaction with peers (which was promoted by the physicality of the input devices) was a major factor for stirring and maintaining children's motivation. One of the teachers stated that children liked to handle the blocks in the hand and see the correspondence between the physical block and the virtual animation.

Further, the teachers pointed out that the tool was a good complement to the traditional storybooks, as children recalled and established relations with the stories they knew but also expanded them creating original story versions. Additionally they referred that the use of TOK sparked a renewed interest in hearing familiar stories such as "The three little pigs", or "Snow white".

The teachers considered that the use of the microphone was a central motivating factor for verbalizing the stories, as children liked to speak into it. In fact, the children always wanted to hold the microphone when they were speaking. Building on their observations the teachers suggested that it would be good if children could record their stories, as hearing them would help children to reflect over their creations, besides allowing teachers and parents to track children's development over time.

One teacher said that TOK helped children that were shyer and quieter as it promoted peer collaboration, but also supported individual interaction. The teachers expressed the wish to use the interface from the beginning of the following school year, starting with a couple of blocks and gradually introducing more. However, they missed different sets of blocks (e.g., animals, transportation, school) to explore different contents. Moreover, teachers referred that they would also use the manipulative system to carry guided activities.

\section{Discussion}

The long-term study (four months) made it possible to observe a significant number of children (24 pairs), who could use the tool on their own during free-playtime. As the children had some initial time to get used to the interface, it was possible to gather data that was not biased by the novelty of the system. One of the participant teachers is using the manipulative system in her class for the third consecutive year, and as she told us, the children continue to play with it regularly.

The physical blocks (used to manipulate the digital content) gave users freedom of movement, supporting children's physical immersion in the story (gesturing, standing up, waving hands or jumping), as well as the embodiment of different characters [4], showing children's enthusiasm and involvement in the task. According to Wright embodiment is "deeply embedded in the children's act of meaning-making itself".

Along with this sensory dimension, which seems to influence the quality of the experience in a positive way, the collaboration supported by the physical blocks - which fostered awareness, control, and availability of actions [71]:4 - strongly contributed to children's involvement in the task, as referred by the [72]:17 teachers and confirmed by the results (the pairs that collaborated played longer with TOK). The mixed pairs seem to bee a good combination for carrying this kind of activities, as together they apparently found a balance between what we have called a game (fight combinations) and story dramatization.

The microphone helped children to coordinate their verbalizations, as the child that held it was also the one that spoke, thus besides being a strong motivational factor the microphone also shaped the interaction, acting as an embodied constraint ([56]:27 and [71]).

As previously referred, this first intervention after TOK's development had an exploratory nature, and sought to understand if the system was intuitive to use, as well as to assess its potential to engage children in activities (within the classroom) that promote the development of oral language and early literacy. Based on our observations, we realized that children quickly understood and appropriated the various mechanisms behind the system to create their stories, engaging mostly in creating narratives or playing language games. The possibility of mixing characters and elements that children know from classic stories (e.g., The three little pigs, Snow white, Zorro) opened up a new creative and exploratory dimension. This, together with the unpredictability generated by the different combinations of story elements, the possibility of actively influencing the story plot, and the availability of various settings provided a framework for creative exploratory tasks, stimulating children's imagination, and triggering new ideas for the construction of narratives, thus creating opportunities for more diversified verbal interactions and extending the opportunities provided by traditional materials. As previously discussed such activities play a major role in the development of oral language and 
early literacy [24,23]. Interestingly, the teachers reported that as TOK motivated children to involve in storytelling it also awakened in them a renewed interest in classical storybooks. They considered that TOK could be used in combination with traditional storybooks, for exploring different dimensions, from narrative to more specific language skills ([73], in press).

\section{Conclusions and future work}

Outgoing from research findings that expressed the need "for research in the design of interactive products for children, related methodology, as well as a scientific account of the interaction between children and technology" [5]:2; as well as the development of technology that meets children's cognitive and motoric needs, instead of merely transposing traditional pedagogical content to a digital format [6]; together with the potential of digital manipulatives to involve children in expressive and exploratory learning activities [2,9], and the need for more long-term evaluations, including evaluations in the classroom $[7,8]$, this study investigated whether a digital manipulative system - TOK - could be used in the classroom, as a tool for supporting the development of oral language skills and emergent literacy. The results showed that TOK was able to provide challenge and adventure, encouraging verbalization and motivating children to collaboratively explore and create narratives. The handling of the physical devices empowered each child to actively participate in the task while promoting peer collaboration.

The results of the study also suggest that pedagogical materials, which are not designed to be explicitly instructional, but instead promote exploratory tasks, verbal interaction and collaboration, have a great potential to foster learning, supporting free but also guided activities within the classroom. This may inform the design of future technology. Thus, besides carrying several design iterations and evaluation sessions with the children, (as shortly summarized in 3.1.) the intervention carried with the functional system further provided valuable insights for the improvement of the interface. Also indicating that the user groups that test the final technology ought to be different than the ones that are involved in the conception and the design in all the other development stages.

The research also showed the importance of a close collaboration between $\mathrm{HCI}$ researchers (Human-Computer-Interaction), language researchers and pre-school teachers that mediate the integration of ICT (Information and Communication Technology) in the classroom in order to fully understand its educational potential.

To conclude, this study describes the implementation of a digital manipulative system in an educational context, showing that it is a useful tool that integrates into high quality learning practices.

In the scope of future work and following teachers' suggestions we plan to incorporate the microphone in the interface and implement a recording function. Further, we intend to develop different kits of blocks (software and hardware) for exploring other curricular subjects. Additionally the team plans to create strategies to involve the community in the exploration of these systems, creating a clubhouse involving parents, teachers and volunteers.

\section{Acknowledgements}

The authors would like to thank the Colégio Teresiano in Braga, specially the children and the teachers who were involved in this study. They also would like to thank Professor Janet Read, who was involved in the study as consultant. This research was supported by FCT-Portuguese Foundation for the Science and the Technology within the Postdoctoral Grant: SFRH/BPD/111891/2015.

\section{References}

[1] C. Sylla, Developing and evaluating pedagogical digital manipulatives for preschool: the case of TOK-touch, organize, create (Doctoral dissertation), 2014. Retrieved from: http://repositorium.sdum.uminho.pt/handle/1822/35672.

[2] M. Resnick, F. Martin, R. Berg, R. Borovoy, V. Colella, K. Kramer, B. Silverman, Digital manipulatives: new toys to think with, in: Proceedings of the Conference on Human Factors in Computing Systems, ACM Press, New York, NY, 1998, pp. 281-287.

[3] C. Sylla, C. Coutinho, P. Branco, Play platforms for children's creativity, in: N. Zagalo, P. Branco (Eds.), Creativity in the Digital Age, in: Springer Series on Cultural Computing, 2015, ISBN: 978-1-4471-6680-1.

[4] C. Sylla, C. Coutinho, P. Branco, A digital manipulative for embodied "stagenarrative" creation, Entertain. Comput. 5 (4) (2014) 495-507. http://dx.doi.org/10.1016/j.entcom.2014.08.011. Elsevier.

[5] J.C. Read, Markopoulos, Child-computer interaction, Int. J. Child-Comput. Interact. 1 (2) (2013).

[6] L. Plowman, J. McPake, C. Stephen, Extending opportunities for learning: the role of digital media in early education, in: S. Suggate, E. Reese (Eds.), Contemporary Debates in Child Development and Education, Routledge, London, 2012.

[7] S. Yarosh, I. Radu, S. Hunter, E. Rosenbaum, Examining values: an analysis of nine examining values: an analysis of nine years of IDC, in: Proceedings of the International Conference on Interaction Design and Children, ACM Press, New York, 2011, pp. 136-144.

[8] L. Amante, The ICT at Elementary School and Kindergarten. Reasons and factors for their integration, Sísifo Educ. Sci. J. 3 (2007) 49-62.

[9] P. Marshall, Do tangible interfaces enhance learning? in: Proceedings of the 1st International Conference on Tangible and Embedded Interaction, ACM press, New York, NY, 2007, pp. 163-170.

[10] M.M. Clay, Emergent reading behavior (Doctoral dissertation), University of Auckland, New Zeeland, 1996.

[11] E.H. Lenneberg, Biological Foundations of Language, Wiley, Oxford, England, 1967.

[12] M.J. Snowling, C. Hulme (Eds.), The Science of Reading, third ed., Blackwell Publishing, USA, UK, Australia, 2009.

[13] J.S. Bruner, Towards a Theory of Instruction, Belknap/Harvard, Cambridge, MA, London, England, 1966.

[14] J. Van Scoter, D. Ellis, J. Railsback, Technology in Early Childhood Education: Finding the Balance, Northwest Regional Educational Laboratory, Portland, OR, 2001.

[15] L.S. Vygotsky, Thought and Language, MIT Press, Cambridge, MA, 1962

[16] C. Lonigan, Vocabulary development and the development of phonological awareness skills in preschool children, in: R.K. Wagner, A.E. Muse, K.R. Tannenbaum (Eds.), Vocabulary Acquisition Implications for Reading Comprehension, The Guildford Press, New York, NY, London, 2007, pp. 15-31.

[17] B.M. Phillips, C.J. Lonigan, Social correlates of emergent literacy, in: M.J. Snowling, C. Hume (Eds.), The Science of Reading, third ed., Blackwell Publishing, USA, UK, and Australia, 2009, pp. 173-187.

[18] E. Sulzby, W. Teale, Emergent literacy, in: R. Barr, M.L. Kamil, P. Mosenthal, P.D. Pearson (Eds.), Handbook of Reading Research II, Lawrence Erlbaum Associates, Mahwah, New Jersey, 1996, pp. 727-757.

[19] W. Teale, E. Sulzby, Emergent literacy as a perspective for examining how young children become writers and readers, in: W. Teale, E. Sulzby (Eds.), Emergent Literacy-Writing and Reading, fourth ed., Ablex Publishing Corporation, Norwood, 1989.

[20] G.J. Whitehurst, C.J. Lonigan, Child development and emergent literacy, Child Dev. 69 (3) (1998) 848-872.

[21] V.G.A. Paley, The Boy Who Would Be A Helicopter, Harvard University Press, Cambridge, MA, 1991.

[22] V.G.A. Paley, Child's Work: The Importance of Fantasy Play, Chicago University Press, Chicago, 2004

[23] F. Collins, The use of traditional storytelling in education to the learning of early literacy skills, Early Child Dev. Care 152 (1)(1999) 77-108.

[24] L.M. Morrow, Retelling stories: A strategy for improving young children's comprehension concept of story structure, and oral language complexity, Elem. Sch. J. 85 (5) (1985) 646-661.

[25] K.M. Speaker, D. Taylor, R. Kamen, Storytelling: Enhancing language acquisition in young children, Education 125 (1) (2004) 3-14.

[26] E. Ackermann, Language games, digital writing, emerging literacies: Enhancing kids' natural gifts as narrators and notators. Bambini Digitali, Strumenti narrativi, scrittura dialogica, TD. Tecnol. Didatt. 24 (3) (2001) 24-48.

[27] J. Cassel, Towards a model of technology and literacy development: Story listening systems, J. Appl. Dev. Psychol. 25 (2004) 75-105

[28] J. Van Scoter, The potential of IT to foster literacy development in kindergarten, in: J. Voogt, G. Knezek (Eds.), International Handbook of Information Technology in Primary and Secondary Education, Part One, Springer, London, 2008, pp. $149-161$ 
[29] J.M. Roschelle, R.D. Pea, C.M. Hoadley, D.N. Gordin, B.M. Means, Changing how and what children learn in school with computer-based technology, Child. Comput. Technol. 10 (2) (2000) 76-101.

[30] L. Plowman, C. Stephen, A "benign addition?" Research on ICT and pre-school children, J. Comput.-Assist. Learn. 19 (2003) 149-164.

[31] J. Marco, E. Cerezo, S. Baldassarri, Bringing tabletop technology to all: evaluating a tangible farm game with kindergarten and special needs children, Pers. Ubiquitous Comput. 17 (2013) 1577-1591.

[32] A. Sandberg, I.P. Samuelsson, Preschool teachers' play experiences then and now, J. Early Child. Res. Pract. 5 (1) (2003).

[33] M. Kamil, S. Intrator, Quantitative trends in publication of research on technology and reading, writing, and literacy, in: T. Shanahan, F. RodríguezBeown (Eds.), National Reading Conference Yearbook. Vol. 47, National Reading Conference, Chicago, IL, 1998, pp. 385-396.

[34] M. Kamil, S. Intrator, H. Kim, The effects of other technologies on literacy and literacy learning, in: M. Kamil, P. Mosenthal, D. Reason, R. Barr (Eds.), Handbook of Reading Research, Vol. 3, Lawrence Erlbaum, NJ, 2000, pp. 771-788.

[35] C. Lankshear, M. Knoebel, New technologies in early childhood literacy research: A review of research, J. Early Child. Lit. 3 (1) (2003) 59-82.

[36] H. Ishii, B. Hullmer, Tangible bits: Towards seamless interfaces between people, bits and atoms, in: Proceedings of the Conference on Human Factors in Computing Systems, ACM Press, New York, 1997, pp. 434-441. http://dx.doi.org/10.1145/258549.258715.

[37] A.J. Druin, D. Proft, B. Bederson, J. Hollan, KidPad: A design collaboration between children, technologists, and educators, in: S. Pemberton (Ed.), Proceedings of the Conference on Human Factors in Computing Systems, ACM Press, New York, NY, 1997, pp. 463-470.

[38] A. Druin, The Role of Children in the Design of New Technology, Technical Report. CS-TR-4058, UMIACS-TR-99-53, The Human-Computer Interaction Laboratory at the University of Maryland, 1999.

[39] S. Benford, B. Bederson, K. Akesson, V. Bayon, A. Druin, P. Hansson, J. Hourcade, R. Ingram, H. Neale, C. O’Malley, K. Simsarian, D. Stanton, Y. Sundblad, G. Taxen, Designing storytelling technologies to encourage collaboration between young children, in: Proceedings of the Conference on Human Factors in Computing Systems, ACM Press, New York, 2000, pp. 224-231.

[40] S. McKenney, J. Voogt, Designing technology for emergent literacy: The PictoPal initiative, Comput. Educ. 52 (4) (2009) 719-729.

[41] E. Rubegni, M. Landoni, Fiabot! Design and evaluation of a mobile storytelling application for schools, in: Proceedings of the International Conference on Interaction Design and Children, ACM Press, New York, 2014, pp. 165-174. http://dx.doi.org/10.1145/2593968.2593979.

[42] F. Pittarello, L. Bertani, CASTOR: learning to create context-sensitive and emotionally engaging narrations in- situ, in: Proceedings of the International Conference on Computer Graphics and Interactive, ACM Press, New York, NY, 2012, pp. 1-10.

[43] D. Kammer, R. Dang, J. Steinhauf, R. Groh, Investigating interaction with tabletops in kindergarten environments, in: Proceedings of the Conference on Interaction Design and Children, ACM Press, New York, NY, 2014, pp. 57-66. http://dx.doi.org/10.1145/2593968.2593975.

[44] L. Flannery, E. Kazakoff, P. Bonta, B. Silverman, M. Bers, M. Resnick, Designing ScratchJr: Support for early chilhood learning through computer programming, in: Proceedings of the 12th International Conference on Interaction Design and Children, ACM Press, New York, NY, 2013, pp. 1-10.

[45] M.S. Horn, S. Al Sulaiman, J. Koh, Translating Roberto to Omar: Computational literacy, sticker books, and cultural forms, in: Proceedings of the Conference on Interaction Design and Children, ACM Press, New York, NY, 2013, pp. 120-127.

[46] M. Billinghurst, H. Kato, I. Poupyrev, The MagicBook-moving seamlessly between reality and virtuality, IEEE Comput. Graph. Appl. 21 (3) (2001) 6-8.

[47] N. Freed, J. Qi, A. Setapen, L. Buechley, C. Breazeal, H. Raffle, Sticking together: Handcrafting personalized communication interfaces, in: Proceedings of the International Conference on Interaction Design and Children, ACM Press, New York, NY, 2011.

[48] A.C. Figueiredo, A.L. Pinto, P. Branco, N. Zagalo, M.E. Coquet, Bridging book: a not-so-electronic children's picture book, in: Proceedings of the 12th International Conference on Interaction Design and Children, ACM Press, New York, NY, 2013, pp. 569-572.

[49] M. Ananny, Telling tales: A new toy for encouraging written literacy through oral storytelling, in: Proceedings of the Biennale Conference Society for Research in Child Development, Minneapolis, 2001.

[50] J. Cassell, K. Ryokai, Making space for voice: Technologies to support children's fantasy and storytelling, J. Pers. Technol. 5 (3) (2001) 203-224.
[51] K. Ryokai, C. Vaucelle, J. Cassell, Virtual peers as partners in storytelling and literacy learning, J. Comput. Assist. Learn. 19 (2) (2003) 195-208.

[52] C. Sylla, S. Gonçalves, P. Branco, C. Coutinho, Peter piper picked a peck of pickled peppers-an interface for playful language exploration, in: Proceedings of the Conference on Human Factors in Computing Systems, ACM Press, New York, NY, 2013, pp. 3127-3130. http://dx.doi.org/10.1145/2468356.2479627.

[53] F. Decortis, A. Rizzo, New active tools for supporting narrative structures, J. Pers. Ubiquitous Comput. 6 (5-6) (2002) 416-429.

[54] H. Raffle, C. Vaucelle, R. Wang, H. Ishii, Jabberstamp: embedding sound and voice in traditional drawings, in: Proceedings of the International Conference on Computer Graphics and Interactive, ACM Press, New York, NY, 2007 pp. $137-144$.

[55] S. Hunter, J. Kalanithi, D. Merrill, Make a riddle and telestory: Designing children's applications for the siftables platform, in: Proceedings of the 9th IDC International Conference on Interaction Design and Children, ACM Press, New York, NY, 2010, pp. 206-209.

[56] E. Hornecker, A design theme for tangible interaction: Embodied facilitation, in: H. Gellersen, et al. (Eds.), Proceedings of the Ninth European Conference on Computer-Supported Cooperative Work, Springer International Publishing, Switzerland, 2005, pp. 18-22.

[57] O. Shaer, E. Hornecker, Tangible user interfaces: Past, present, and future directions, J. Found. Trends Hum.-Comput. Interact. Arch. 3 (1-2) (2010) $1-137$.

[58] B. Ullmer, H. Ishii, Emerging frameworks for tangible user interfaces, in: J.M. Carroll (Ed.), Human-Computer Interaction in the New Millennium, Addison-Wesley, 2001, pp. 579-601.

[59] T. Anderson, J. Shattuck, Design-based research: A decade of progress in education research, Educ. Res. 41 (1) (2012) 16-25.

[60] P. Bell, On the theoretical breadth of design-based research in education, Educ. Psychol. 39 (4) (2004) 243-253.

[61] S. Barab, K. Squire, Design-based research: Putting a stake in the ground, J Learn. Sci. 13 (1)(2004) 1-14. http://dx.doi.org/10.1207/s15327809jls1301_1.

[62] P. Cobb, A. diSessa, R. Lehrer, L. Schauble, Design experiments in educational research, Educ. Res. 32 (1) (2003) 9-13.

[63] B. Shneiderman, C. Plaisant, Designing the User Interface: Strategies for Effective Human-Computer Interaction, fourth ed., Addison-Wesley, Boston, 2004.

[64] J.P. Hourcade, Interaction design and children, J. Found. Trends Hum.-Comput Interact. 1 (4) (2008) 277-392. http://dx.doi.org/10.1561/1100000006.

[65] A.J. Greimas, Actants, actors, and figures. On meaning: Selected writings in semiotic theory, in: Theory and History of Literature, Vol. 38, U of Minnesota P, Minneapolis, 1973, pp. 106-120. Trans. Paul J. Perron and Frank H, Collins, 1987.

[66] W. Bos, C. Tarnai, Content analysis in empirical social research, Int. J. Educ. Res. 31 (1) (1999) 659-671.

[67] C.P. Coutinho, Metodologia de Investigação em Ciências Sociais e Humanas: Teoria e Prática, second ed., Almedina, Coimbra, 2013.

[68] J. Cohen, A coefficient of agreement for nominal scales, Educa. Psychol. Meas. 20 (1) (1960) 37-46.

[69] M. Resnick, B. Myers, K. Nakakoji, B. Schneiderman, R. Pausch, M. Eisenberg, Design principles for tools to support creative thinking, Inst. Softw. Res. (2005). Paper 816.

[70] L. Ermi, F. Mäyrä, Fundamental components of the gameplay experience: analyzing immersion, in: Proceedings of the Conference on Digital Games Research Association, Vancouver, 2005.

[71] N. Yuill, Y. Rogers, Mechanisms for collaboration: A design and evaluation framework for multi-user interfaces, in: Proceedings of the Conference Transactions on Computer-Human Interactions, ACM-Transactions, 2012 p. 1901-01.

[72] S. Wright, Graphic-narrative play: Young children's authoring through drawing and telling, Int. J. Educ. Arts 8 (8) (2007) 1-27.

[73] C. Sylla, I.S.P. Pereira, C. Coutinho, P. Branco, Digital manipulatives as scaffolds for pre-schoolers' language development, IEEE Trans. Emerg. Top. Comput. (2016) in press.

\section{Further reading}

[1] V. Propp, Morphology of the Folktale, second ed., University of Texas Press, Austin, 1928-1968, Trans., Laurence Scott.

[2] O. Zuckerman, A. Gal-Oz, To TUI or not to TUI: Evaluating performance and preference in tangible vs. graphical user interfaces, Int. J. Hum.-Comput. Stud. 71 (2013) 803-820. 